\title{
Título: El conocimiento profesional de profesores de Nivel Polimodal de la ciudad de Corrientes. Concepciones de Enseñanza y Aprendizaje en el discurso docente y su relación con la práctica
}

\author{
Autora: Patricia B. Demuth Mercado ${ }^{1}$
}

\begin{abstract}
El presente resumen de investigación corresponde al trabajo de tesis de Licenciatura en Ciencias de la Educación de la Facultad de Humanidades de la Universidad Nacional del Nordeste defendido en el año 2007 dirigido por la Mg. Ma. Teresa Alcalá.
\end{abstract}

El tema seleccionado se ubica en el ámbito de estudio de la Didáctica General, y profundizó especialmente la problemática sobre el Conocimiento Profesional Docente como aspecto fundamental para la comprensión de los procesos educativos relacionados con esta tarea. A su vez, entendiendo que todas las concepciones que el docente posee, constituyen una parte fundamental de su conocimiento profesional, aspecto que influye directamente en la toma de decisiones didácticas.

La problemática señalada fue abordada desde las concepciones de enseñanza y de aprendizaje presentes en el discurso docente, y su relación con la práctica educativa de nivel Polimodal en diferentes instituciones educativas de la Ciudad de Corrientes. Los objetivos de investigación se centraron en la descripción e interpretación de los discursos docentes en relación con las concepciones de enseñanza, de aprendizaje y en articulación con las prácticas educativas; la identificación de aspectos teóricos, prácticos explícitos e implícitos que inciden en la conformación de tales concepciones y la elaboración de categorías clasificatorias del meta-discurso de los formadores.

El trabajo realizado correspondió a una investigación descriptiva-explicativa. Se optó por un estudio cualitativo, ya que se pretendía la comprensión del conocimiento de los profesores en la búsqueda de un mejor conocimiento de la práctica educativa y por ende, en la posibilidad de transformación para la mejora.

Los docentes que participaron de la investigación eran docentes del Nivel Polimodal de variadas instituciones educativas, tanto de gestión pública como privada, de la ciudad de Corrientes, poseían titulación docente y pertenecían a diferentes áreas: Ciencias Sociales (Historia y Geografía), Ciencias Exactas (Matemática, Física y Química), Ciencias Humanísticas (Ciencias de la Educación y Filosofía), Ciencias Naturales (Biología), Lengua, Lenguas Extranjeras.

La malla metodológica se diseñó para su aplicación y análisis en tres fases diferentes: $1^{\mathrm{a}}$ ) se procedió a la aplicación de un cuestionario abierto autoadministrado de 18 ítemes agrupados en tres aspectos fundamentales: concepciones didácticas (ligadas a la enseñanza, ligadas al aprendizaje, ligadas a la evaluación) concepciones epistemológicas (ligadas al conocimiento científico), y un relato de la práctica docente.

\footnotetext{
${ }^{1}$ Doctoranda de investigación por la Universidad de Sevilla, carrera doctoral en Didáctica y Organización de Instituciones Educativas. Especialista en Cs. Sociales, Profesora y Licenciada en Cs. de la Educación. Auxiliar Docente Ordinaria de Primera Categoría en la Cátedra Didáctica I/Didáctica General de la Facultad de Humanidades-UNNE.
} 
$2^{a}$ ) se seleccionó un grupo menor de docentes. Dicha selección se basó en las respuestas que los docentes brindaron en el cuestionario, a partir de éstas se procedió a observaciones no participantes de clases, para la elaboración de una guía abierta tentativa que dio lugar a la $3^{a}$ ) tercera fase que incluyó diferentes entrevistas en profundidad. Las tres fases se relacionan siguiendo el criterio de recursividad, ya que cada una de ellas sirvió como insumo para la proyección de la siguiente.

En la primera fase del trabajo de campo se contó con los 24 docentes y en la segunda y tercer fase se redujo a 4 docentes que fueron observados y entrevistados en profundidad.

Las concepciones de enseñanza y aprendizaje de los docentes se pudieron describir y analizar a partir de la identificación de los roles que se juegan en el aula, de las reflexiones acerca del aprendizaje y las actividades propuestas, de las decisiones tomadas en la planificación áulica y las observaciones de clase, y de los instrumentos de evaluación utilizados que dieron cuenta de la importancia que los docentes brindan a determinados aprendizajes.

A lo largo del trabajo de investigación quedó manifiesta la complejidad del Conocimiento Profesional Docente, ya que las concepciones de enseñanza, las concepciones de aprendizaje, y la relación de ambas con la práctica educativa se encontraron en diferentes niveles de formulación y realización en cada individuo. Además, el trabajo de reflexión, indagación y estudio con los docentes confirmó de manera clara que es la práctica docente, la experiencia en las aulas, en las instituciones y en los diferentes contextos de la realidad las que condicionan fuertemente la construcción del Conocimiento Profesional Docente, limitando, transformando, o en algunos casos resignando, sus concepciones "teóricas" previas y/o actuales construidas en procesos de formación académica (inicial y/o permanente).

Se percibió una leve evolución en las concepciones docentes hacia un modelo alternativo que propone caminos de aprendizaje más autónomos e independientes. La caracterización y puesta en práctica de su tarea, de manera coherente y relacionada con lo afirmado por los docentes, no sólo en la primera instancia sino en la reflexión sobre sus mismas afirmaciones, manifestó un grado de conciencia importante en el desarrollo de su profesión.

La profundización en las concepciones de los docentes a partir de las diferentes fases planteadas permite afirmar que son producto de la cultura educativa generalizada sin mayores particularidades, con una fuerte presencia de modelos tradicionales con rasgos alternativos, de teorías que entienden al aprendizaje como asimilación de significados y de concepciones epistemológicas empiristas que subyacen a las prácticas.

A partir de este trabajo se continúa con indagaciones en la temática, considerando que sólo su conocimiento certero permitiría orientar el cambio en estas verdaderas teorías implícitas de los docentes, fundamento de las actuaciones de la práctica educativa. 